Preprint

\title{
Review of Cathodic Arc Deposition Technology at the Start of the New Millennium
}

D.M. Sanders, A. Anders

This article was submitted to The $27^{\text {th }}$ International Conference on Metallurgical Coatings and Thin Films, San Diego, CA, April 10-14, 2000

Lawrence

Livermore

National

Laboratory

February 24, 2000

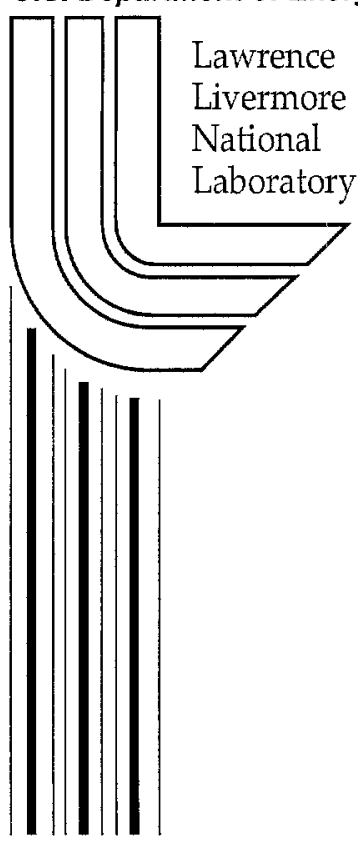




\section{DISCLAIMER}

This document was prepared as an account of work sponsored by an agency of the United States Government. Neither the United States Government nor the University of California nor any of their employees, makes any warranty, express or implied, or assumes any legal liability or responsibility for the accuracy, completeness, or usefulness of any information, apparatus, product, or process disclosed, or represents that its use would not infringe privately owned rights. Reference herein to any specific commercial product, process, or service by trade name, trademark, manufacturer, or otherwise, does not necessarily constitute or imply its endorsement, recommendation, or favoring by the United States Government or the University of California. The views and opinions of authors expressed herein do not necessarily state or reflect those of the United States Government or the University of California, and shall not be used for advertising or product endorsement purposes.

This is a preprint of a paper intended for publication in a journal or proceedings. Since changes may be made before publication, this preprint is made available with the understanding that it will not be cited or reproduced without the permission of the author.

This work was performed under the auspices of the United States Department of Energy by the University of California, Lawrence Livermore National Laboratory under contract No. W-7405-Eng-48.

This report has been reproduced directly from the best available copy.

Available electronically at http://www.doc.gov/bridge

Available for a processing fee to U.S. Department of Energy

And its contractors in paper from

U.S. Department of Energy

Office of Scientific and Technical Information

P.O. Box 62

Oak Ridge, TN 37831-0062

Telephone: (865) 576-8401

Facsimile: (865) 576-5728

E-mail: reports@adonis.osti.gov

Available for the sale to the public from

U.S. Department of Commerce

National Technical Information Service

5285 Port Royal Road

Springfield, VA 22161

Telephone: (800) 553-6847

Facsimile: (703) 605-6900

E-mail: orders@ntis.fedworld.gov

Online ordering: http://www.ntis.gov/ordering.htm

OR

Lawrence Livermore National Laboratory

Technical Information Department's Digital Library

http://www.llnl.gov/tid/Library.html 
The 27th International Conference on

Metallurgical Coatings and Thin Films

ICMCTF2000

April $10-14,2000$,

San Diego, California

Review of Cathodic Arc Deposition Technology at the Start of the New Millennium

David M. Sanders ${ }^{\mathrm{a}}$ and André Anders ${ }^{\mathrm{b}}$

a) Lawrence Livermore National Laboratory, Livermore, CA 94550

b) Lawrence Berkeley National Laboratory, 1 Cyclotron Road, MS 53

Berkeley, CA 94720

\begin{abstract}
The vacuum cathodic arc has been known to provide a means of producing coatings since the second half of the 19th century. This makes it one of the oldest known means for making coatings in a vacuum. In the last century it has been recognized that the copious quantities of ions produced by the process offers certain advantages in terms of coating properties. Specifically, ions can be steered and/or accelerated toward the parts to be coated. This, in turn, can provide enhanced adhesion, film density, and composition stoichiometry in the case of compound coatings. The ions generated by the cathodic arc have high "natural" kinetic energy values in the range $20-200 \mathrm{eV}$, leading to enhanced surface mobility during the deposition process and even ion subplantation. In many cases, dense coatings are achieved even when non-normal arrival angles are involved. The ion energy can further manipulated by the plasma immersion biasing technique. The issue of macroparticle contamination has been addressed by a variety of novel plasma filters. In spite of all of these advantages, this deposition technique has not been widely adopted in
\end{abstract}


the western nations for commercial coating except in the case of enhancing the performance of cutting tools.

The purpose of the this review is to explore reasons for this lack of general use of the technology and to point out some encouraging recent developments which may lead to its accelerated adoption for a much wider variety of applications in the near future.

Keywords: Vacuum arcs, cathodic arcs, arc plasma deposition, macroparticle filtering, review 


\section{Introduction}

The use of a vacuum arc for generating coatings was first suggested by Thomas Edison who was awarded a patent on arc plasma deposition in 1892 [1]. Ever since then the approach has been investigated by many groups around the world who have been intrigued by the promise of an efficient source of highly ionized material for producing dense, adherent coatings having a wide range of composition. Now at the start of this new millennium and more than a century later, the great potential offered by the technology still remains to be fully exploited.

There are two main reasons for this failure to capitalize on a recognized opportunity. Both result from basic characteristics of the cathodic arc. The location of the cathodic arc(s) on the target has been traditionally a challenge to control with continuous arc systems leading in some cases to process instabilities. Cathodic arcs normally generate undesirable macroparticles which, if not filtered from the plasma stream, end up as defects in the coatings. While numerous approaches have been proposed for controlling the arc and filtering the plasma of macroparticles, relatively few sources have been commercially available, particularly for generating defect-free coatings over large areas in a manner analogous to that which is possible with commercially available linear magnetrons or advanced e-beam systems. In the last few years great progress has been made on both fronts. The purpose of the current review is to point out recent developments and changes in both the science and commercialization of the technology which are expected to result in the acceleration of its adoption for new applications.

\section{Plasma production and properties}

The arc discharge current is concentrated at the cathode surface, forming non-stationary locations of extremely high current density (of order $10^{12} \mathrm{~A} / \mathrm{m}^{2}$ ): cathode spots. The high current density is associated with an extremely high areal power density (of order $10^{13} \mathrm{~W} / \mathrm{m}^{2}$ ) which in turn provides the conditions for the localized phase transformation from the solid (the cathode material) to a fully ionized plasma [2]. Apart from a few exceptions, cathodic arc plasmas contain multiply ionized ions. The ion charge state distributions are enhanced at early discharge times, and they become quasi-stationary for discharge times greater than $100 \mu \mathrm{s}$. Experimental data for 50 cathode elements have been measured by Brown [3]. These data are explained in form of a Periodic Table of material and plasma properties [4]. It 
has been shown that ion charge states can be enhanced (typically up to a factor 2) by magnetic fields and other methods $[5,6]$. The flux of neutral metal vapor is usually negligible compared to the flux of ions, and therefore the traditional term deposition by "arc evaporation" is a misnomer from a strict physics point of view. A better term is "cathodic arc plasma deposition."

The characteristic time constants of cathode spots were found in the sub-microsecond range, and their characteristic size is often as small as $1 \mu \mathrm{m}$. The specifics depend on the material and on the surface conditions [7]. Although modeling of non-stationary cathode spots is very difficult, enough progress has been made over the last two decades to understand the basic mechanisms of spot operation (see, for instance, the review by Beilis [8]. Interestingly, pulsed and DC arcs operate qualitatively the same way. However, the action of the arc changes the cathode surface conditions thereby representing a feedback mechanisms that influences arc spot evolution.

The plasma produced at cathode spots expands rapidly into the vacuum ambient. Interestingly, the observed final ion velocities are in the range $1-2 \times 10^{4} \mathrm{~m} / \mathrm{s}$, almost independent of the cathode material and ion charge state. This fact has been satisfactory explained and is largely due to electron-ion coupling $[9,10]$. The directed ion velocities are supersonic and correspond to about $20 \mathrm{eV}$ for light elements and $200 \mathrm{eV}$ for heavy elements. These high ion energies are the major reason for the different film properties obtained by cathodic arc plasma deposition.

Cathode spots are not only the source of fully ionized plasma but also of droplets and debris particles, commonly referred to as macroparticles. There is a large number of articles that report about production and size distribution of macroparticles, e.g. $[11,12]$. Although most publications quote the size range $0.1-10 \mu \mathrm{m}$, the lower boundary reflects the limits of diagnostics instrumentation rather than a true limit of the size distribution. Nanoparticles are abundant but difficult to detect and characterize. The term "macroparticles" should be understood generically for all particles that are much larger than ions, atoms, and clusters. Macroparticle prevention or removal is perhaps the most important issue for the future of cathodic arc plasma deposition. The conventional and most successful approach is magnetic filtering (see below).

\section{Modes (Pulsed vs. continuous operation)}


The decision whether to use a continuous or a pulsed mode of operation depends largely on the goal to be accomplished. Large area, high-throughput deposition of relatively thick films calls for DC operation. DC systems are capable of very high deposition rates. That is particularly true when the coating does not require reduction or elimination of macroparticles (see below). Virtually all commercially used cathodic arc systems operate today in DC mode.

In contrast, pulsed systems have a relatively small deposition rate due to the small duty factor:

$$
R_{p u l s e d}=\delta R_{D C}
$$

where the duty factor is defined by $\delta=t_{\text {on }} /\left(t_{o n}+t_{\text {off }}\right)$, the ratio of the arc on-time to the duration of the pulse cycle. The advantage of pulsed operation is mainly related to the significantly reduced requirements of cooling because the average power can be kept low (e.g. less than $1 \mathrm{~kW}$ ).

It has been demonstrated that average deposition rate of pulsed system can reach or even surpass the rate of conventional DC arc equipment. The High Current Arc (HCA) [13] and Filtered High Current Arc $(\phi-\mathrm{HCA})[14]$ utilizes arc currents in the kiloampere range and operates with high pulse repetition rates and duty factor. Of course, the small-power-feature does not apply to HCA systems.

Pulsed operation can be motivated for other reasons: the film properties and their controllability can be enhanced by using the pulsed mode. For instance, a-C films deposited by pulsed carbon vacuum arcs tend to have a slightly higher $\mathrm{sp}^{3}$ content than their DC-deposited counterparts (for details see the Applications section). However, pulsed operation does not always lead to enhanced properties. Most importantly, metal films produced by pulsed deposition with low duty factor exhibit the usually unwanted incorporation of oxygen and hydrogen [15]. The origin of the contamination is subject of ongoing research but it seems to be clear that at least a fraction of the contamination comes from the water layer which forms on the cathode surface between arc pulses [16], even when working in high vacuum.

Pulsed systems can be of great advantage if ultrathin a-C and oxide films are to be deposited. Suitable systems can be designed in a surprisingly compact manner [17-21] thus allowing the customer to readily retrofit existing deposition facilities with cathodic arc systems.

\section{Plasma Transport and Macroparticle Filters}


One important advantage of the cathodic arc process is the formation of a copious quantity of ions of the target material composition. This is in contrast to other physical vapor deposition techniques such magnetron sputtering and electron beam evaporation where the depositing species forming the coating are primarily neutral atoms. In may cases, the ions generated by the cathodic arc are multi-charged and with a near optimal kinetic energy for forming dense and adherent coatings on complex shapes.

In contrast to magnetron sputtering and electron beam evaporation where the distribution of deposition atoms forming the coating are primarily neutral, the charged particles produced by the cathodic arc process can be controlled both with respect to the path taken from the arc target to the part being coating and the kinetic energy with which they strike the part being coated.

In addition to providing the basis for filtering unwanted macroparticles from the plasma stream as discussed in the next section, the ability to control the path of the plasma flow from the arc target to the part to be coated leads in turn to the ability to enhance coating uniformity in a way analogous to the spraying of paint uniformly over a surface. The direction of the plasma can be accomplished either by a set of electromagnetic coils driven by a time-varying power supply or by moving permanent magnets. The principles for such direction are the same as discussed in the next section on macroparticle filtering.

\subsection{Macroparticle filtering}

Macroparticle filters are used to separate and remove particles from the cathodic arc plasma stream. Originally introduced by Aksenov and coworkers in the 1970s [22, 23], a variety of filters of different geometries, size, and parameters are in operation today. Filtering of cathodic arc plasmas has been reviewed a number of times [24-29] and therefore we will only give a brief overview here and emphasize new developments.

\subsubsection{Principle of magnetic filtering}

The presence of an axial magnetic field, the motion of electrons is bound to magnetic field lines. They spiral around the field line until they suffer a collision with another particle. If the magnetic field is bent, such the field inside a curved coil, electrons follow the bent curvature. Such electrons are said to be 
magnetized. In contrast, ions are usually not magnetized because their gyration radius is much larger than the gyration radius of electrons and larger than the characteristic size of the filter. Nevertheless, ions are forced to follow the magnetic field lines due to the electric fields between electrons and ions which form if ions are shifted from electrons. The plasma stays macroscopically electrically neutral. Plasma transport along magnetic field lines is therefore a combined magnetic (electrons) and electric (ions) mechanism.

Macroparticles may be slightly charged but the mass-to charge ratio is vastly greater than the corresponding ratio for electrons and ions, and therefore macroparticles move along almost straight trajectories due to their inertia. If the plasma (electrons and ions) are guided outside line-of-sight from the cathode surface, macroparticle will be separated from the plasma thus complete macroparticle removal by magnetic filtering would have accomplished if there were not additional issues. These issues are: macroparticle reflection from walls, significant plasma losses in the filter, and nanoparticle transport by plasma-particle interaction ("plasma wind").

\subsubsection{Design of magnetic macroparticle filters}

Magnetic macroparticle filters can be categorized by their architecture (closed or open), mode of operation (pulsed versus DC), and geometry. The classic $90^{\circ}$ duct filter $[22,23]$, the $45^{\circ}$ Knee-Filter [30], and rectilinear filters [31] are examples of closed architecture filters. They are characterized by an enclosure, the "duct", which is surrounded by magnetic field coils. Macroparticles cannot leave the filter volume. They are expected to stick to the duct wall or to be caught between baffles which are placed inside the duct. Catching macroparticles is difficult for some cathode materials such as carbon because the macroparticles tend to be elastically reflected from surfaces [32]. This "bouncing" issue is addressed by filters of open-architecture where macroparticles leave the region of plasma transport. Filters of open architecture do not have a duct but consist of a few turns of a magnetic field coil [17, 33, 34], allowing the macroparticles to escape the plasma volume without sticking to walls. DC-operated filters are usually of closed architecture while open filters are preferred for pulsed operation.

\subsubsection{Filter and system efficiency}


One important parameter of a filter is its plasma transport efficiency which can be defined as the ratio of the number of ions leaving the filter to the number entering it. However, it is often difficult to determine the ion flux into the filter, and a less ambiguous value is the ratio of filtered ion current and arc

current. It is advisable to use this ratio, "system coefficient", $\kappa=I_{i, \text { fittered }} / I_{\text {arc }}$, characterizing not only the filter but the coupled arc source and filter system [28]. It is important to understand that the filter's plasma transport efficiency may (hypothetically) reach $100 \%$, however the system coefficient by definition can never reach $100 \%$ because electrons carry most of the arc current. The system coefficient is typically about one percent.

\subsection{Recent Filter Developments}

\subsubsection{Improvements to the classic $90^{\circ}$ duct and similar closed-architecture filters}

For good plasma transport, the duct must be biased with respect to the plasma, typically to about +10 to $+25 \mathrm{~V}$ [35], an effect already noted in the pioneering work of Aksenov and coworkers $[22,23]$. This feature was used by Bilek and coworkers [36,37], who showed that applying a positive bias to a strip electrode that is located near the outer wall of the interior of the duct produces an effect comparable to biasing the whole duct. The strip electrode is elegant solution because biasing the duct wall may be questionable since the wall is often used as the vacuum enclosure which is grounded for safety reasons.

The plasma transport of pulsed High Current Arcs (HCA [38]) was investigated using $30^{\circ}$ duct filter segments similar to the classic $90^{\circ}$ filter. The system coefficient was very high: up to $7 \%$ [39]. The arc can be triggered in a very controlled fashion by a pulsed laser ("Laser Arc" [40, 41]). The filtered HCA system developed at the Fraunhofer Institute operates with very high currents (peak $5 \mathrm{kA}$ ) and arc repetition frequency (up to $300 \mathrm{~Hz}$ ). Although the arc is pulsed, the magnetic field is DC-powered, like most other filters of closed architecture. The $30^{\circ}$ duct segments can be combined to form a filter of desired length and bending angle, including off-plane geometry. A closed-architecture filter with off-plane geometry was recently developed at the Nanyang Technical University, Singapore [42]. 
Macroparticle reflection can be minimized by sophisticated baffle structures which are inserted into the duct. Plasma transport can be improved with increasing magnetic guiding field, although the improvement is not as significant as the effect of wall biasing.

Plasma output from the filter can be magnetically horizontally and vertically rastered ("paintbrush principle") in order to improve homogeneity of coating over a relatively large area [30]. Typical substrate sizes are up to $1000 \mathrm{~cm}^{2}$. For even larger areas, rectilinear source and filters are needed.

\subsubsection{Improvements to open-architecture filters}

Open-architecture filters are often used with pulsed systems. They can be easily miniaturized thus are suitable for the thin film deposition on small-area substrates. An example of an improved openarchitecture filter is the off-plane Twist Filter, described in a separate paper presented at this conference [21].

A completely different design of an open architecture filter is Ryabchikov's linear Ventian blind filter [43] which is a set of current-carrying vanes or baffles ("Ventian blinds"). Bilek and coworkers [44] found that this type of filter works well when the current of the vanes exceed $1 \mathrm{kA}$, however, the plasma flux is patterned unless the substrate is placed far from the filter.

\subsubsection{Rectilinear filters}

Independent of the coating technology chosen, to coat large areas, one has a choice of using multiple sources with associated power supplies or moving the parts under a single linear source for each required coating composition. In most commercial large area installations, the linear source option is chosen. Linear sources have been available for several decades for a magnetron sputtering-based coating systems and for cathodic arc systems where there is no attempt was made to filter the plasma stream. Unfortunately, until very recently, linear sources based on the filtered cathodic arc have not been available. The recent appearance of linear filtered cathodic arc sources from multiple vendors represents a major advance which is likely to accelerate the development of new applications for filtered cathodic arc technology where there is a need to coat large areas $[31,45,46]$. 
In the last year a linear filtered arc source capable of depositing carbon in a continuous arc mode has been demonstrated by the Aksenov and coworkers [31] and the Gorokhovsky team. Gorokhovsky's source is described in a series of earlier patents [47-49]. This development represents a major advance because carbon is one of the most difficult materials to manage in the continuous arc mode. Unlike most materials, the electrical resistivity of carbon decreases with temperature. This, coupled with the porous nature of most commonly available graphite targets, results in a slowly moving arc which has a tendency to bore holes in the target and extinguish itself. Figure 1 shows a schematic of this filter with measurement of the titanium ion current which is measured as a function of the current to the anode separator, one of the operational variables which can be adjusted with this particular filter. Figure 2 shows the racetrack of a graphite target which has been operated for several hours. Notice that there is good utilization of target material.

\subsubsection{Other than magnetic macroparticle filters}

Other than magnetic filters have been explored. For instance, some filters types use mechanical blades or shutters to block macroparticles $[28,50]$. Kang and co-workers suggested enhancing the natural particle-plasma separation by rotating the cathode at very high speeds $(4200 \mathrm{r} / \mathrm{min})$. Indeed, they found that most particles can be centrifuged, and plasma deposition with much less particles was demonstrated [51]. However mechanical approaches seem to be not practicable for industrial applications.

A purely electrostatic filter has been presented by Meyer and Scheibe [52] but details are not yet disclosed.

\section{Spatial and Energetic Manipulation of Plasma Particles}

As pointed out earlier, the cathodic arc plasma is fully ionized. Neutral metal vapor (atoms) may be present due to evaporation from macroparticles and previously active but still hot spot sides. Macroparticle filtering removes the neutrals as well, and therefore the plasma leaving the filter and streaming toward the substrate consists only of charged particles: ions and electrons. Biasing the substrate negatively with respect to the plasma potential (or, equivalently, changing the plasma potential positively with respect to the substrate potential) gives rise to an electric sheath at the substrate which acts on all 
charged particles. Biasing is a technique used for decades but its potential can only be fully employed if the plasma is fully ionized. With substrate biasing, the great potential of cathodic arc plasmas can be utilized because the energy of all plasma particles arriving at the surface can be tailored. That is a key difference to PVD techniques using neutral vapors (thermal and electron beam evaporation) or slightly ionized plasmas (sputtering).

The technique of biasing has been greatly extended by going to pulses of very high bias voltages in the range to many tens of kilovolt: ions are accelerated in the sheath and implanted into the substrate or workpiece. The to-be-implanted substrate is immersed into the processing plasma. The fascinating idea of this ion implantation approach is the elimination of the need for ion beam extraction, focusing, transport, analysis, scanning and other manipulations. These are some of the advantages of Plasma Immersion Ion Implantation (PIII). The concept was introduced with nitrogen plasmas in 1986 [53]. Nitrogen plasmas were dominant in the early PIII years because one could form sub-surface nitrides at relatively low temperatures with excellent mechanical and chemical properties. In the following years, the physical basis has been developed by a number of groups, and new applications have been explored (see the series of proceedings of PIII workshops [54-57] and the Handbook [58]).

If condensable plasma species such as metal ions of cathodic arc plasma are involved, the PIII concept translates into a novel hybrid ion implantation and ion deposition technique [59]. Pulsing the substrate implies a high-energy phases (bias pulse on, ion implantation) and a low-energy phases (bias pulse off, ion deposition). If cathodic arc plasmas are used, the term MePIIID (pronounced "me-pit", Metal Plasma Ion Immersion Implantation and Deposition) is used (for a review see [60]).

The bias voltage can be adjusted during the process. For instance, one can use high voltage (many $\mathrm{kV}$ ) for the beginning phase, leading the substrate cleaning by sputtering and formation of an atomically intermixed layer, followed by a deposition phases in which low-voltage bias acts like ion assisted deposition. MePIIID with low voltage can be understood as self-ion-assisted deposition process: no "foreign" species such as argon ions are needed.

Another interesting feature of MePIIID is that depth profiles of species can be synthesized that are not attainable by pure ion implantation (due to sputter limit) and vapor deposition (absence of intermixed layer). Brown [61] dubbed this approach "pseudo-implantation. 
Interestingly, when a PIII technique is used for a film-forming process, such as MePIIID, the pulsed bias voltage is often not very high. In fact, a couple hundred volts are well suitable for the MePIIID-synthesis of a-C (amorphous carbon) films, using filtered carbon vacuum arc plasma. From a certain point of view, the low-energy limit of film-forming PIII techniques are similar to biased deposition technique developed before PIII was invented.

\section{Film Growth}

A detailed discussion of the effect of energetic particles produced by the cathodic arc process on film growth is an appropriate subject for it's own review and well beyond the scope of this current work. One such review is given by Martin [62]. A brief overview will be provided here to illustrate the principles involved.

A popular macroscopic description for coating microstructures generated during film growth is the structure-zone model originally described by Movschan and Demchishin [63] and later expanded by Thornton [64] and Messier [65, 66]. This model predicts that coating microstructure is determined by a competition between the rate at which coating add-atoms arrive at the surface of the coating being formed and the rate with which those atoms are able to rearrange themselves before new atoms arrive. According to this model, denser coatings result from slower deposition rates and higher substrate temperatures since such conditions provide more time and energy for coating atoms to diffuse to form coating microstructures more similar to bulk material. In the context of this model, the energetic ions produced by the cathodic arc process lead to denser coatings at lower deposition temperatures.

Additional insight into the effect of energetic particles on thin film growth is given in a review by Hubler and Sprague [67]. They point out that ion bombardment of the coating surface influences gas adsorption behavior by increasing the sticking coefficient of normally non-reactive gases such as nitrogen and changing the nature of adsorption sites from lower energy physi-sorption sites to higher energy chemisorption sites. These concepts explain why the cathodic arc process is so effective in forming nitrides $[42$, 68] and carbides [69] during reactive deposition of compound coatings.

The carbon system provides an example of how non-equilibrium bonding can be achieved in a coating due to the higher kinetic energy of the ions generated by the cathodic arc process. Using either 
pulsed or continuous filtered cathodic arcs, numerous investigators [17, 20,31, 32, 70-89] have produced coatings which have a high $\mathrm{sp}^{3}$ bonding more characteristic of diamond or a high $\mathrm{sp}^{2}$ content more characteristic of graphite. Subplantation, which can be considered as ultrashallow implantation, is a generally accepted model for formation of $\mathrm{sp}^{3}$-rich carbon films [90-92]. As reviewed by Stanishevsky [20], the $\mathrm{sp}^{3} / \mathrm{sp}^{2}$ ratio in carbon coatings can be adjusted over a wide range from 4 to .25 with a corresponding change in microhardness from greater than $90 \mathrm{GPa}$ to less than $40 \mathrm{GPa}$. The corresponding electrical resistivity varies from greater than $10^{8}$ to $10^{-1} \mathrm{Ohm}-\mathrm{cm}$. As seen in the atomic force micrographs reproduced from Stanishevsky [20] in Fig. 3, the coatings with high $\mathrm{sp}^{3} / \mathrm{sp}^{2}$ ratio are much smoother than those with the low $\mathrm{sp}^{3} / \mathrm{sp}^{2}$ ratio.

The ion energy can be manipulated by the electric fields of a sheath which forms to accommodate the difference of substrate potential and plasma potential. The sheath voltage and thus ion energy can be readily changed by biasing the substrate ( $c f$. MePIIID, section 5 ). This can be used to improve adhesion and other film properties. For instance, hard carbon (a-C or dlc) films show a strong dependence of their properties on the carbon ion energy $[73,89,93-95]$. This is illustrated in a very impressive way by the synthesis of carbon-carbon multiplayers in which the individual layers are grown at alternating bias amplitude [74, 82]. For instance, Fig. 4 shows a TEM picture of a carbon-carbon multilayer grown by alternating pulsed bias from $-2000 \mathrm{~V}$ (relatively low density and $\mathrm{sp}^{3} / \mathrm{sp}^{2}$ ratio, bright contrast) and $-100 \mathrm{~V}$ (relatively high density, high $\mathrm{sp}^{3} / \mathrm{sp}^{2}$ ratio, dark contrast). It was found that the multilayers had lower stress in comparison to monolithic films of the same hardness and thickness.

\section{Emerging Applications}

As mentioned earlier, the major commercial application for cathodic arc technology is in the enhancement of useful life for cutting tools [96]. This is likely the case because major benefits in tool life were achieved despite the presence of macroparticles in the coatings. With the advent of commercially available arc filters, we expect to see new applications which depend on being able to produce macroparticle-free coatings. While many of these applications are still tightly protected trade secrets, we have listed some examples below which have been reported in the open literature. 


\subsection{Example: Corrosion protection of dies}

Fig 5 shows a comparison of the corrosion behavior of some die pins which has been given a variety of different surface treatments and subsequently exposed to molten aluminum. The sample which was pre-nitrided and subsequently coated with a TiN/TiBCN multilayer coating using a filtered cathodic arc showed virtually no corrosion in this hostile environment. Fig. 6 shows the ability of a similar coating to protect a die part from thermal cycle cracking. Once again, this application requires filtering of the arc since macroparticles in the coating would provide a path for the corrosive media to find its way to the underlying part. This demonstrated success of this filtered arc coatings for corrosion protection suggests additional applications may become practical such as the replacement of chromium coatings currently generated by electroplating, a process which is causing environmental concern.

\subsection{Example: Hard Carbon Films}

As discussed earlier, cathodic arc deposited carbon is a particularly interesting system because of the wide variety of coating structures and morphologies which can be generated. Potential applications for coatings produced by a filtered arc abound. It has been suggested that they may have value in protecting knife edges and surgical blades since extremely hard smooth coatings are possible. They may prove useful for bearing surfaces in high precision machine tools for the same reason [97, 98]. Electron emissive carbon coatings [99] suitable for flat panel displays have been demonstrated [70, 71], and electron emission from vacuum-arc a-C coated nanotubes is being investigated [100].

Thin carbon films synthesized by filtered arc deposition have been investigated for several years as protective coatings of read-write heads (sliders) and magnetic hard disks [73, 101, 102]. The magnetic storage industry is working towards a storage density of $100 \mathrm{~Gb} / \mathrm{in}^{2}$, requiring not thin but ultrathin $(<5$ $\mathrm{nm}$ ), continuous, dense, hard and elastic ("tough") protective layers, allowing the magnetic spacing between slider and disk to be about $10 \mathrm{~nm}$. Cathodic arc systems with advanced filters such as the Twist Filter [21] may represent a possible avenue for synthesizing ultrathin films showing the required features. It is well established that arc-deposited a-C films are the most "diamondlike" (they may have more than $80 \%$

$\mathrm{sp}^{3}$ bonds). However, pulsed-arc synthesized carbon films can be very hard and elastic even when $\mathrm{sp}^{2}$ bonds dominate, provided the graphene sheets are curved [103]. The range of carbon-based materials is still growing and we should be prepared to see more interesting properties discovered. 


\subsection{Example: Nitrides, Oxides, Carbides and other Coatings}

Cathodic arc deposition of TiN coatings is a well established technology $[42,68]$ which is in the process of fine-tuning process control and film properties. The deposition of other nitrides, oxides and carbides has been demonstrated $[69,104,105]$ but it is still in its early phase of development. Oxide films grown by pulsed arc deposition may contain significant amounts of hydrogen [15]. Interesting progress has been made towards unusual cathode materials such as boron [106]; potential application include the deposition of c-BN films. Attempts to deposit the theoretically predicted superhard phase $\beta-C_{3} \mathrm{~N}_{4}$ using filtered carbon arc plasma have been unsuccessful (see e.g., [107]), as have all attempts using other approaches. Multi-element films such as mullite films $\left(\mathrm{Al}_{2} \mathrm{O}_{3}-\mathrm{SiO}_{2}\right)$ [108] have been deposited using a dual plasma source technique $[105,108]$. Mullite films can be used as high-temperature protective layers in aggressive environments.

\subsection{Example: Barrier Layers and Trench Metallization}

Future generations of integrated circuits (ICs) require "wiring" or interconnection of their internal elements at even smaller dimensions than today. In the present $250 \mathrm{~nm}$ generation of ICs, aluminum is the metal of choice for in-plane interconnection, and tungsten is used for connections between layers ("vias"). Recently, copper-based metallization of ICs has been introduced. Copper has a lower resistivity, allowing the introduction of even finer "wires", resulting in shorter on-chip resistance-capacitance (RC) time delays, i.e. operation at high tact frequencies. The higher mass and melting point of copper make it significantly less susceptible to electromigration than aluminum. However, copper poisons silicon by diffusion [109]. This requires a diffusion barrier such as a tantalum and tantalum nitride thin layer.

The present trend in IC fabrication is towards using the dual-damascene process. Vias and trenches are etched into dielectric layers and filled with the metal, and the component is finally chemicalmechanical polished to produce a planarized structure. Conventional PVD techniques such as sputter deposition and evaporation have failed to fill trenches with high aspect ratio (depth:width). Clogging of trenches occurs before filling is complete, leaving voids inside the metallic conductors. Improved trench filling has been achieved with collimated sputtering [110], or sources that have a high degree of ionization 
such as self-sputtering [111], electron cyclotron resonance (ECR) [112], or vacuum arc plasma sources [113]. These methods have shown various degrees of success but failed to fill trenches with aspect ratios greater than $4: 1$ in trenches less than $180 \mathrm{~nm}$ wide because of inadequate control over the particle (ions and atoms) velocity distribution and ion energy.

Using filtered cathodic arcs and pulsed bias (MePIIID), Monteiro [114, 115] has demonstrated the filling of trenches as narrow as $100 \mathrm{~nm}$, with an aspect ratio as high as 9:1. The ability to tailor the step coverage and the deposition mode resulted from the high directionality of the ion flux and the tight control of the energy of the depositing ions. It was possible to fill trenches without blocking the trench entrance (Fig. 7) when the copper deposition was carried out using a pulse bias voltage of $-100 \mathrm{~V}$ at bias duty cycle of $50 \%$. The same process was used to deposit highly conformal tantalum films on trenches and vias etched on $\mathrm{SiO}_{2}$. In this case, a bias duty cycle of $12.5 \%$ was used to deposit 10,20 , and $30 \mathrm{~nm}$ thick tantalum films with thickness variation better than $15 \%$ across the entire trench. Fig. 8 shows the image of a $20 \mathrm{~nm}$ Ta film on trenches of $130 \mathrm{~nm}$ width and aspect ratio 7:1. These results demonstrate the remarkable progress made over the last years in improving the utilization of cathodic arc plasmas. Implementation of these impressive $R \& D$ results into industrial processes will depend on the perception and prototyping investment by the semiconductor industry.

\section{Summary and Outlook}

Although cathodic arc deposition is one of the first plasma technologies, its wide-spread industrial application is hampered by a few drawbacks that are being addressed in recent years. Most importantly, remarkable progress has been made in scaling arc devices for the deposition of very large substrate areas, and macroparticle filters have been developed that meet even the stringent requirements of the magnetic storage industry. The driving force to pursue arc technology, as opposed to evaporation and sputtering technologies, are the often outstanding properties of the films deposited. Film properties can be readily tuned and tailored because cathodic arc plasmas are fully ionized. The plasma density distribution and the ion energy distribution can be manipulated with magnetic and electric (bias) fields, respectively. Cathodic arc deposition technology is going beyond the traditional arc "evaporation" for hard coatings. New 
applications emerge such as a-C coatings for wear and corrosion protection and as electron field emitter. One may speculate that the progress shown in terms of cathode spot control on carbon cathodes and the development of rectilinear filters may enable further progress in operating DC cathodic arcs with other semimetal and semiconductor materials such as silicon, boron, and certain carbides.

\section{Acknowledgements}

We gratefully acknowledge the help and support of many colleagues who granted permission for using their data and figures. In particular we thank Ian Brown, Othon Monteiro, Vladimir Gorokhovsky and Deepak Bhat. This work was supported by the Advanced Energy Projects and Technology Research Division, U.S. Department of Energy, under Lawrence Livermore National Laboratory under contract number W-7405-ENG-48 and Lawrence Berkeley Laboratory contract number DE-AC03-76SF00098. 


\section{Figure Captions}

Fig. 1: Schematic of linear filtered arc system developed by the Gorokhovsky team. Courtesy of V. Gorokhovsky.

Fig. 2: Photograph of graphite target operated in linear cathodic arc source. Photo courtesy of V. Gorokhovsky.

Fig. 3: Atomic force micrographs of carbon deposited with $\mathrm{sp}^{3} / \mathrm{sp}^{2}$ ratio of 4 (a) and 0.1 (b). Note that the vertical scale varies. Photos courtesy of A. Stanishevsky

Fig. 4: TEM picture of a carbon-carbon multilayer grown by alternating pulsed bias from $-2000 \mathrm{~V}$ and $-100 \mathrm{~V}$

Fig. 5: Comparison of corrosion resistance of die pins treated with various surface treatments, the most successful being a duplex coating with a filtered arc multilayer coating. Courtesy of $D$. Bhat

Fig. 6: Comparison of thermal fatigue behavior of coated and uncoated die pins. The multilayer produced in the filtered cathodic arc system prevents surface cracking that is found in the uncoated part. Courtesy of D. Bhat.

Fig. 7: Copper trench filling using the MePIIID process (filter cathodic arc with tailored pulse biasing); (a) shows an example of premature closing of trench avoided by the MePIIID process (b) discussed in the text. Figure courtesy of $\mathrm{O}$. Monteiro

Fig. 8: Deposition of $20 \mathrm{~nm}$ tantalum diffusion barrier with 7:1 aspect ratio using the MePIIID process, figure courtesy of $\mathrm{O}$. Monteiro 


\section{References:}

[1] T. A. Edison, Process of duplicating phonograms, Patent U.S. 484 582, October 18, 1892.

[2] B. Jüttner, IEEE Trans. Plasma Sci. PS-15 (1987) 474-480.

[3] I. G. Brown, Rev. Sci. Instrum. 65 (1994) 3061-3081.

[4] A. Anders, Phys. Rev. E 55 (1997) 969-981.

[5] E. Oks, I. G. Brown, M. R. Dickinson, R. A. MacGill, P. Spädtke, H. Emig, and B. H. Wolf, Appl. Phys. Lett. 67 (1995) 200-202.

[6] E. Oks, A. Anders, I. G. Brown, M. R. Dickinson, and R. A. MacGill, IEEE Trans. Plasma Sci. 24 (1996) 1174-1783.

[7] B. Jüttner, J. Phys. D: Appl. Phys. 28 (1995) 516-522.

[8] I. I. Beilis, "State of the theory of cathode spot phenomena in vacuum arcs," presented at Proc. 17th Int. Symp. on Discharges and Electrical Insulation in Vacuum, Berkeley, 1996, 188-193.

[9] C. Wieckert, Contrib. Plasma Phys. 27 (1987) 309-330.

[10] E. Hantzsche, IEEE Transactions of Plasma Science 23 (1995) 893-898.

[11] J. E. Daalder, J. Phys. D: Appl. Phys. 9 (1976) 2379-2395.

[12] S. Anders, A. Anders, K. M. Yu, X. Y. Yao, and I. G. Brown, IEEE Trans. Plasma Sci. 21 (1993) $440-446$.

[13] P. Siemroth, T. Schülke, and T. Witke, Surf. Coat. Technol. 68 (1994) 314-319.

[14] T. Witke and P. Siemroth, IEEE Trans. Plasma Sci. 27 (1999) 1039-1044.

[15] J. M. Schneider, A. Anders, B. Hjörvarsson, I. Petrov, K. Macak, U. Helmerson, and J.-E. Sundgren, Appl. Phys. Lett. 74 (1999) 200-202.

[16] G. Y. Yushkov and A. Anders, IEEE Trans. Plasma Sci. 26 (1998) 220-226.

[17] J. Koskinen, A. Anttila, and J.-P. Hirvonen, Surf. Coat. Technol. 47 (1991) 180-187.

[18] S. Anders, A. Anders, and I. Brown, J. Appl. Phys. 74 (1993) 4239-4241.

[19] A. Anttila, J. Salo, and R. Lappalainen, Mat. Letters 24 (1995) 153-156.

[20] A. Stanishevsky, Chaos, Solitons \& Fractals 10 (1999) 2045-2066.

[21] A. Anders and R. A. MacGill, Surf. \& Coat. Technol. (2000) presented at the 27th ICMCTF, San Diego, April 10-14, 2000. 
[22] I. I. Aksenov, V. A. Belous, V. G. Padalka, and V. M. Khoroshikh, Sov. J. Plasma Phys. 4 (1978) 425-428.

[23] I. I. Aksenov, V. A. Belous, and V. G. Padalka, Instrum. Exp. Tech. 21 (1978) 1416-1418.

[24] D. M. Sanders, D. B. Boercker, and S. Falabella, IEEE Trans. Plasma Sci. 18 (1990) 883-894.

[25] R. L. Boxman and S. Goldsmith, Surf. \& Coat. Technol. 52 (1992) 39-50.

[26] R. L. Boxman, V. Zhitomirsky, B. Alterkop, E. Gidalevitch, I. Beilis, M. Keidar, and S. Goldsmith, Surf. \& Coat. Technol 86-87 (1996) 243-253.

[27] I. G. Brown, "Cathodic Arc Deposition of Films," in Annual Review of Materials Science, vol. 28.

Palo Alto, CA: Annual Reviews, Inc., 1998, pp. 243-269.

[28] A. Anders, Surf. \& Coat. Technol. 120-121 (1999) 319-330.

[29] M. Hakovirta, V. M. Tiainen, and P. Pekko, Diamond and Related Materials 8 (1999) 1183-1192.

[30] D. A. Baldwin and S. Fallabella, "Deposition processes utilizing a new filtered cathodic arc source," presented at Proc. of the 38th Annual Techn. Conf., Society of Vacuum Coaters, 1995, 309-316.

[31] I. I. Aksenov, V. A. Belous, V. V. Vasil'ev, Y. Y. Volkov, and V. E. Strel'nitskij, Diam. Relat. Mater. 8 (1999) 468-471.

[32] T. Schülke and A. Anders, Plasma Sources Sci. Technol. 8 (1999) 567-571.

[33] J. Storer, J. E. Galvin, and I. G. Brown, J. Appl. Phys. 66 (1989) 5245-5250.

[34] M. M. M. Bilek and A. Anders, Plasma Sources Sci. Technol. 8 (1999) 488-493.

[35] A. Anders, S. Anders, and I. G. Brown, J. Appl. Phys. 75 (1994) 4900-4905.

[36] M. M. M. Bilek, D. R. McKenzie, Y. Yin, M. U. Chhowalla, and W. I. Milne, IEEE Trans. Plasma Sci. 24 (1996) 1291-1298.

[37] M. M. M. Bilek, Y. Yin, and D. R. McKenzie, IEEE Trans. Plasma Sci. 24 (1996) 1165-1173.

[38] T. Witke, T. Schülke, B. Schultrich, P. Siemroth, and J. Vetter, "Comparison of filtered high current pulsed arc deposition ( $\phi-\mathrm{HCA})$ with conventional vacuum arc methods," presented at Int. Conf. Plasma Surface Engineering, Garmisch-Patenkirchen, Germany, 1998,

[39] T. Schülke, A. Anders, and P. Siemroth, IEEE Trans. Plasma Sci. 25 (1997) 660-664.

[40] H. J. Scheibe, D. Drescher, B. Schultrich, M. Falz, G. Leonhardt, and R. Wilberg, Surf. \& Coatings Technol. 85 (1996) 209-214. 
[41] H. J. Scheibe, B. Schultrich, R. Wilberg, and M. Falz, Surf. Coat. Technol. (1997) 410-413.

[42] B. K. Tay, X. Shi, H. S. Yang, H. S. Tan, D. Chua, and S. Y. Teo, Surf. \& Coat. Technol. 111 (1999) 229-233.

[43] A. I. Ryabchikov, Surf. \& Coat. Technol. 96 (1997) 9-15.

[44] M. M. M. Bilek, A. Anders, and I. G. Brown, IEEE Trans. Plasma Sci. 27 (1999) 1197-1202.

[45] R. P. Welty, Rectangular vacuum-arc plasma source, Patent 5,480,527, Jan. 2, 1996.

[46] R. P. Welty, "Linear magnetron arc cathode and macroparticle filter," presented at Int. Conf. Metal. Coat. \& Thin Films, San Diego, 1999, paper B1-5.

[47] V. Gorokhovsky, Apparatus for Application of Coatings in Vacuum, Rectangular Filter, Patent 5435900 , July 25, 1995 .

[48] V. Gorokhovsky, Vacuum-Arc Plasma Source, Patent 5380421, Jan. 10, 1995.

[49] V. Gorokhovsky, Arc Assisted CVD Coating and Sintering Method, Patent 5587207, Dec. 24, 1996.

[50] T. Utsumi and J. H. English, J. Appl. Phys. 46 (1975) 126-131.

[51] G. H. Kang, H. Uchida, and E. S. Koh, Surf. Coat. Technol. 68/69 (1994) 141-145.

[52] C. F. Meyer and H.-J. Scheibe, "Filtered Laser-Arc: A new technology for deposition of particlefree films," presented at Int. Conf. Metal. Coat. \& Thin Films (ICMCTF), San Diego, 1999, paper B4-9.

[53] J. R. Conrad, J. L. Radtke, R. A. Dodd, F. J. Worzala, and N. C. Tran, J. Appl. Phys. 62 (1987) $4591-4596$.

[54] J. Vac. Sci. Technol. B 12 (1994) 815-998.

[55] Surf. \& Coat. Technol. 85 (1996) 1-124.

[56] Surf. \& Coat. Technol. 93 (1997) 157-342.

[57] J. Vac. Sci. Technol. B 17 (1999) 798-899.

[58] A. Anders, "Handbook of Plasma Immersion Ion Implantation and Deposition," . New York: John Wiley \& Sons, 2000.

[59] I. G. Brown, X. Godechot, and K. M. Yu, Appl. Phys. Lett. 58 (1991) 1392-1394.

[60] A. Anders, Surf. \& Coat. Technol. 93 (1997) 157-167. 
[61] I. G. Brown, A. Anders, S. Anders, R. A. Castro, M. R. Dickinson, R. A. MacGill, and Z. Wang, Nucl. Instrum. Meth. Phys. Res. B 106 (1995) 646-650.

[62] P. J. Martin, S. Falabella, and D. M. Karpov, "Coatings from the vacuum arc deposition," in Handbook of Vacuum Arc Science and Technology, R. L. Boxman, P. J. Martin, and D. M. Sanders, Eds. Park Ridge: Noyes, 1995, pp. 367-551.

[63] B. A. a. D. Movchan, A.V., Fiz. Metallov Metalloved. 28 (1969) 653-660.

[64] J. A. Thornton, J. Vac. Sci. \& Technol. 11 (1974) 666-670.

[65] R. Messier, J. Vac. Sci. Technol. A4 (1986) 490-495.

[66] R. Messier, A. P. Giri, and R. A. Roy, J. Vac. Sci. Technol, A2 (1984) 500-503.

[67] G. K. Hubler and J. A. Sprague, "Energetic particles in PVD technology: particle-surface interaction processes and energy-particle relationships in thin film deposition,", 1996, 29-35.

[68] P. J. Martin, A. Bendavid, T. J. Kinder, and L. Wielunski, Surf. \& Coat. Technol. 87 (1996) 271278.

[69] P. J. Martin, R. P. Netterfield, T. J. Kinder, and L. Descotes, Surf. Coat. Technol. 49 (1991) 239. 243.

[70] B. F. Coll, J. Jaskie, J. Markham, E. Menu, and A. Talin, "Preparation of disordered amorphous and partially ordered nano clustered carbon films by arc deposition: a critical review,", 1998, 91-116.

[71] B. F. Coll, J. E. Jaskie, J. L. Markham, E. P. Menu, A. A. Talin, and P. Von Allmen, "Field emission properties of disordered and partially ordered nano clustered carbon films,", 1998, 185-96.

[72] S. Anders, A. Anders, C. S. Bhatia, S. Raoux, D. Schneider, J. W. Ager III, and I. G. Brown, "Properties of vacuum arc deposited amorphous hard carbon films," presented at 3rd International Conference on the Application of Diamond Films and Related Materials, Gaithersburg, Maryland, 1995, 809-812.

[73] G. M. Pharr, D. L. Callahan, D. McAdams, T. Y. Tsui, S. Anders, A. Anders, J. W. Ager, I. G. Brown, C. S. Bhatia, S. R. P. Silva, and J. Robertson, Appl. Phys. Lett. 68 (1996) 779-781.

[74] S. Anders, A. Anders, J. W. Ager III, Z. Wang, G. M. Pharr, T. Y. Tsui, I. G. Brown, and C. S. Bhatia, Mat. Res. Soc. Symp. Proc. 383 (1995) 453-458.

[75] T. Ishigaki, Y. Moriyoshi, T. Watanabe, and A. Kanzawa, J. Mat. Res. 11 (1996) 2811-24. 
[76] S. Anders, C. S. Bhatia, W. Fong, R. Y. Lo, and D. B. Bogy, Mat Res. Soc. Proc. 517 (1998) 371-

382.

[77] O. R. Monteiro, M.-P. Delplancke-Ogletree, and I. G. Brown, Thin Solid Films 342 (1999) 100107.

[78] S. Anders, J. Diaz, J. W. Ager III, R. Y. Lo, and D. B. Bogy, Appl. Phys. Lett. 71 (1997) 33673369.

[79] B. Marchon, P. N. Vo, M. R. Khan, and J. W. Ager, IEEE Trans. Magn. 27 (1991) 5160-5162.

[80] M. Chhowalla, C. A. Davis, M. Weiler, B. Kleinsorge, and G. A. J. Amaratunga, J. Appl. Phys. 79 (1996) 2237-2244.

[81] S. Anders, J. W. Ager III, G. M. Pharr, T. Y. Tsui, and I. G. Brown, Thin Solid Films 308-309 (1997) $186-190$.

[82] S. Anders, D. L. Callahan, G. M. Pharr, T. Y. Tsui, and C. S. Bhatia, Surf. Coat. Technol. 94/95 (1997) 189-194.

[83] J. W. Ager III, S. Anders, A. Anders, and I. G. Brown, Appl. Phys. Lett. 66 (1995) 3444-3446.

[84] M. C. Salvadori, R. M. Galvao, O. R. Monteiro, and I. G. Brown, Thin Solid Films 325 (1998) 1923.

[85] D. R. McKenzie, D. Muller, B. A. Pailthorpe, Z. H. Wang, E. Kravtchinskaya, D. Segal, P. B. Lukins, P. D. Swift, P. J. Martin, G. Amaratunga, P. H. Gaskell, and A. Saeed, Diamond \& Rel. Mater. 1 (1991) 51-59.

[86] S. Anders, A. Anders, I. G. Brown, B. Wei, K. Komvopoulos, J. W. Ager, and K. M. Yu, Surf. Coat. Technol. 68/69 (1994) 388-393.

[87] E. G. Gerstner, D. R. McKenzie, M. K. Puchert, P. Y. Timbell, and J. Zou, J. Vac. Sci. Technol. A 13 (1995) 406-411.

[88] B. F. Coll, P. Sathrum, R. Aharonov, and M. A. Tamor, Thin Solid Films 209 (1992) 165-173.

[89] B. K. Tay, X. Shi, D. I. Flynn, and Z. Sun, Surf. Eng. 13 (1997) 213-217.

[90] Y. Lifshitz, S. R. Kasai, J. W. Rabalais, and W. Eckstein, Phys. Rev. B 41 (1990) 10468-10480.

[91] Y. Lifshitz, G. D. Lempert, and E. Grossman, Phys. Rev. Lett. 72 (1994) 2753-2756.

[92] S. Uhlmann, T. Fraunheim, and Y. Lifshitz, Phys. Rev. Lett. 81 (1998) 641-644. 
[93] B. K. Tay, X. Shi, H. S. Tan, Z. Li, and Y. Tu, "The effect of substrate bias on selected properties of ta-C films deposited by FCVA technique," presented at 3rd International Conference on the Applications of Diamond Films and Related Materials, Gaithersburg, MD, 1995, 901-904.

[94] E. Grossman, G. D. Lempert, J. Kulik, D. Marton, J. W. Rabalais, and Y. Lifshitz, Appl. Phys. Lett. 68 (1996) 1214-1216.

[95] Y. Lifshitz, G. D. Lempert, S. Rotter, I. Aviga1, C. Uzan-Saguy, R. Kalish, D. Marton, and J. W. Rabalais, Diamond \& Rel. Mater. 3 (1994) 542-546.

[96] J. Vetter and A. J. Perry, "Applications of Arc-Deposited Coatings," in Handbook of Vacuum Arc Science and Technology, R. L. Boxman, P. J. Martin, and D. M. Sanders, Eds. Park Ridge, N.J.: Noyes, 1995, pp. 493-519.

[97] T. Witke, T. Schuelke, J. Berthold, C. F. Meyer, and B. Schultrich, Surf. \& Coat. Technol. 116119 (1999) 609-613.

[98] B. Schultrich, H. J. Scheibe, D. Drescher, and H. Ziegele, Surf. \& Coat. Technol. 98 (1998) 10971101.

[99] A. V. Karabutov, V. I. Konov, V. G. Ralchenko, E. D. Obraztsova, V. D. Frolov, S. A. Uglov, H.J. Scheibe, V. E. Strelnitskij, and V. I. Polyakov, Diamond \& Rel. Materials 7 (1998) 802-806.

[100] S. Dimitrijevic, J. C. Withers, V. Mammana, O. R. Monteiro, J. W. Ager III, and I. G. Brown, Appl. Phys. Lett. 75 (1999) 2680-2682.

[101] S. Anders, I. G. Brown, C. S. Bhatia, and D. B. Bogy, Data Storage 4 (1997) 31-38.

[102] C. S. Bhatia, S. Anders, K. Bobb, R. Hsiao, D. B. Bogy, and I. G. Brown, J. Tribology 120 (1998) 795-799.

[103] I. Alexandrou, H.-J. Scheibe, C. J. Kiel, A. J. Papworth, G. A. J. Amaratunga, and B. Schultrich, Phys. Rev. B 60 (1999) 10903-10907.

[104] S. Anders, A. Anders, M. Rubin, Z. Wang, S. Raoux, F. Kong, and I. G. Brown, Surf. Coat. Technol. 76 (1995) 167-173.

[105] O. R. Monteiro, M.-P. Delplancke-Ogletree, R. Y. Lo, R. Winand, and I. G. Brown, Surf. \& Coat. Technol. 94-95 (1997) 220-225. 
[106] F. Richter, G. Flemming, M. Kühn, S. Peter, and H. Wagner, Surf. \& Coat. Technol. 112 (1999) $43-47$.

[107] C. Spaeth, M. Kuhn, T. Chudoba, and F. Richter, Surf. \& Coat. Technol. 112 (1999) 140-145.

[108] O. R. Monteiro, Z. Wang, and I. G. Brown, J. Mater. Res. 12 (1997) 2401-2410.

[109] E. R. Weber, Appl. Phys. A 30 (1983) 1-22.

[110] S. M. Rossnagel and R. J. Sward, J. Vac. Sci. Technol. A 13 (1995) 156-158.

[111] A. Sano, H. Kotani, H. Sakaue, S. Shingubara, T. Tagahagi, Y. Horike, and Z. J. Radzimirski, presented at Advanced Metallization of ULSI Applications, Portland, Oregon, 1995, 709.

[112] C. A. Nichols, S. M. Rossnagel, and S. Hamaguchi, J. Vacuum Sci. Technol. B 14 (1996) 32703275 .

[113] P. Siemroth, C. Wenzel, W. Kliomes, B. Schultrich, and T. Schülke, Thin Solid Films 308 (1997) $455-459$.

[114] O. R. Monteiro, J. Vac. Sci. Technol. A 17 (1999) 1094-1097.

[115] O. R. Monteiro, I. G. Ivanov, D. Papanayiotou, I. G. Brown, and C. Ting, "On integration of vacuum arc plasma deposited diffusion barrier films and electroplated copper films," presented at Advanced Metallization Conference, Orlando, FL, 1999, 
Fig. 1: Schematic of linear filtered arc system developed by the Gorokhovsky team. Courtesy of V. Gorokhovsky.
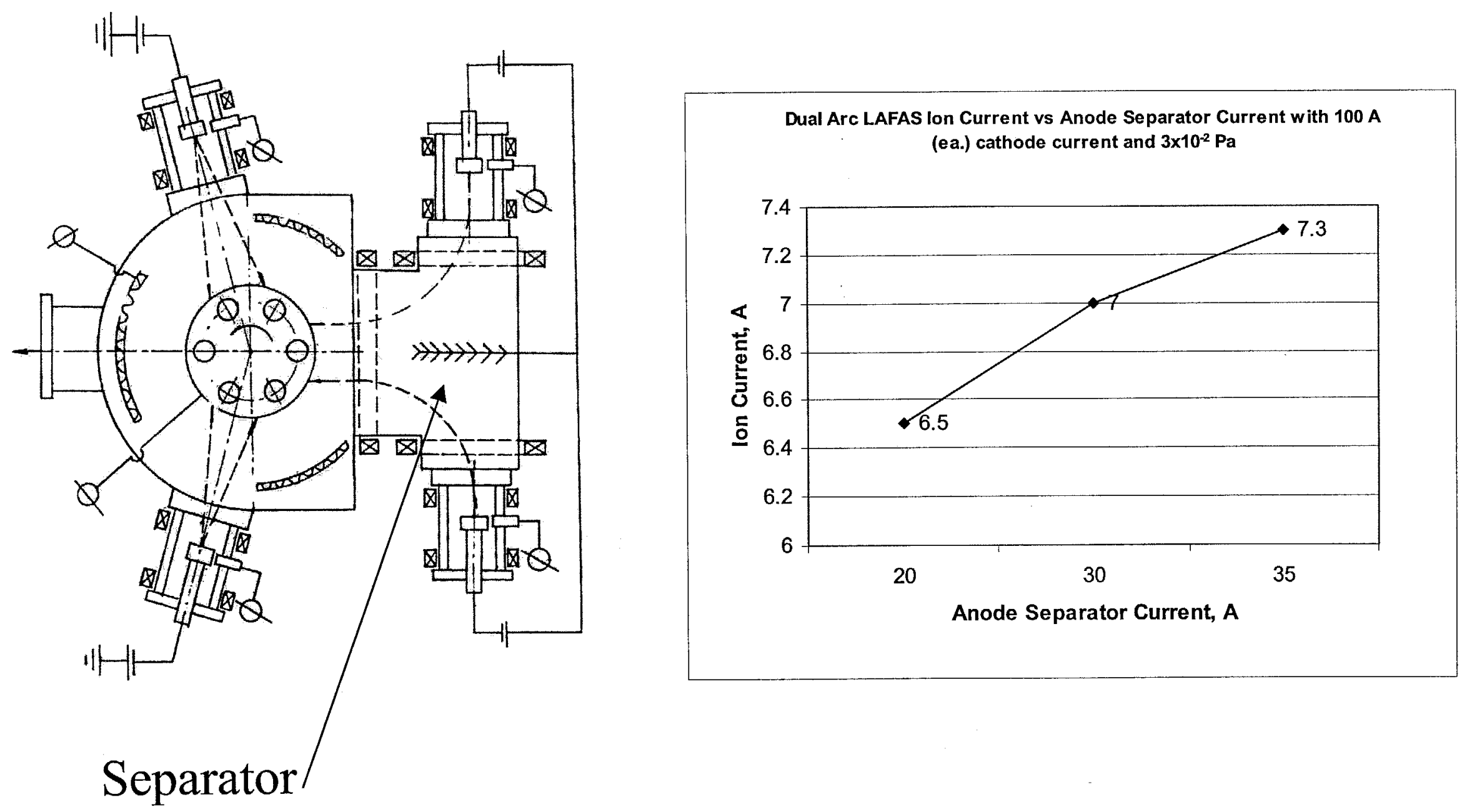
Fig. 2: Photograph of graphite target operated in linear cathodic arc source. Photo courtesy of V. Gorokhovsky.

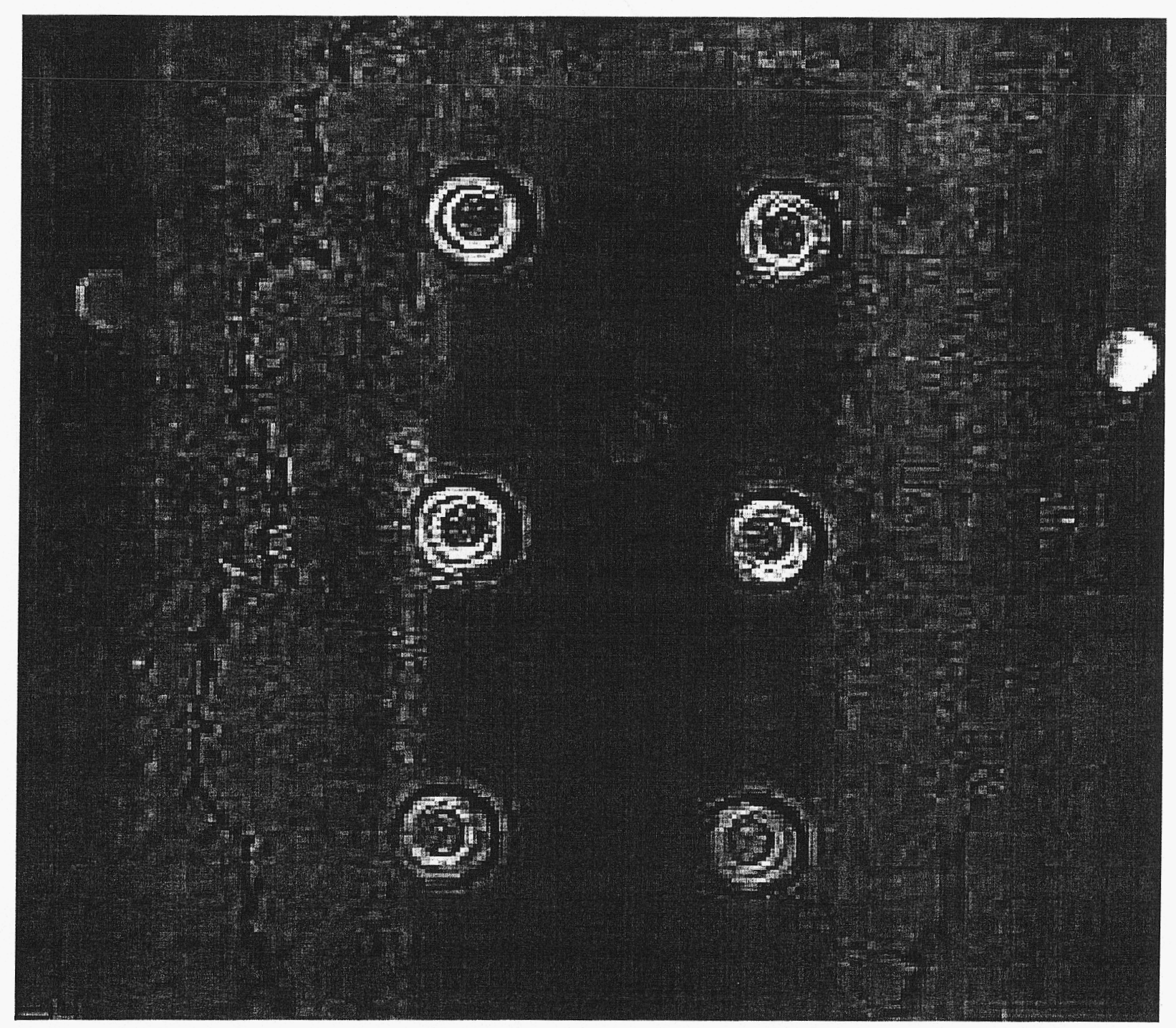


Fig. 3: Atomic force micrographs of carbon deposited with $\mathrm{sp}^{3} / \mathrm{sp}^{2}$ ratio of 4 (a) and 0.1 (b) . Note that the vertical scale varies. Photos courtesy of A. Stanishevsky
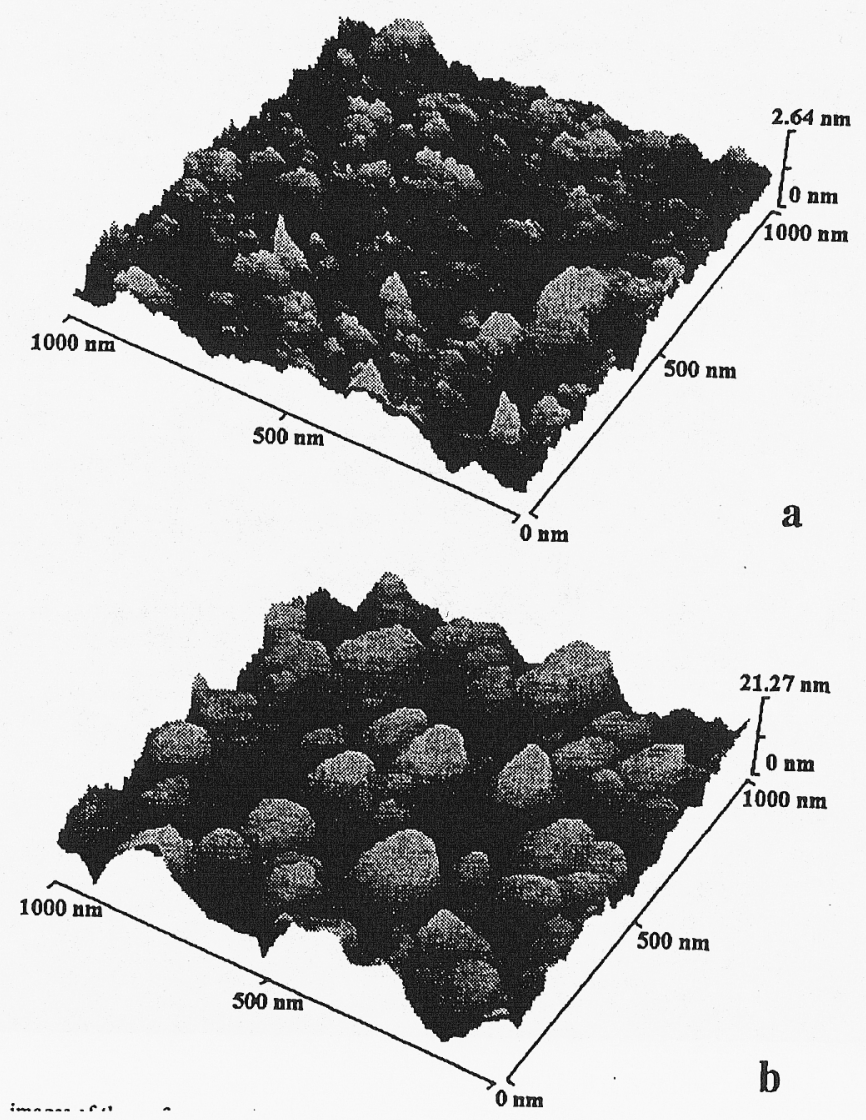
Fig. 4: TEM picture of a carbon-carbon multilayer grown by alternating pulsed bias from $-2000 \mathrm{~V}$ and $-100 \mathrm{~V}$

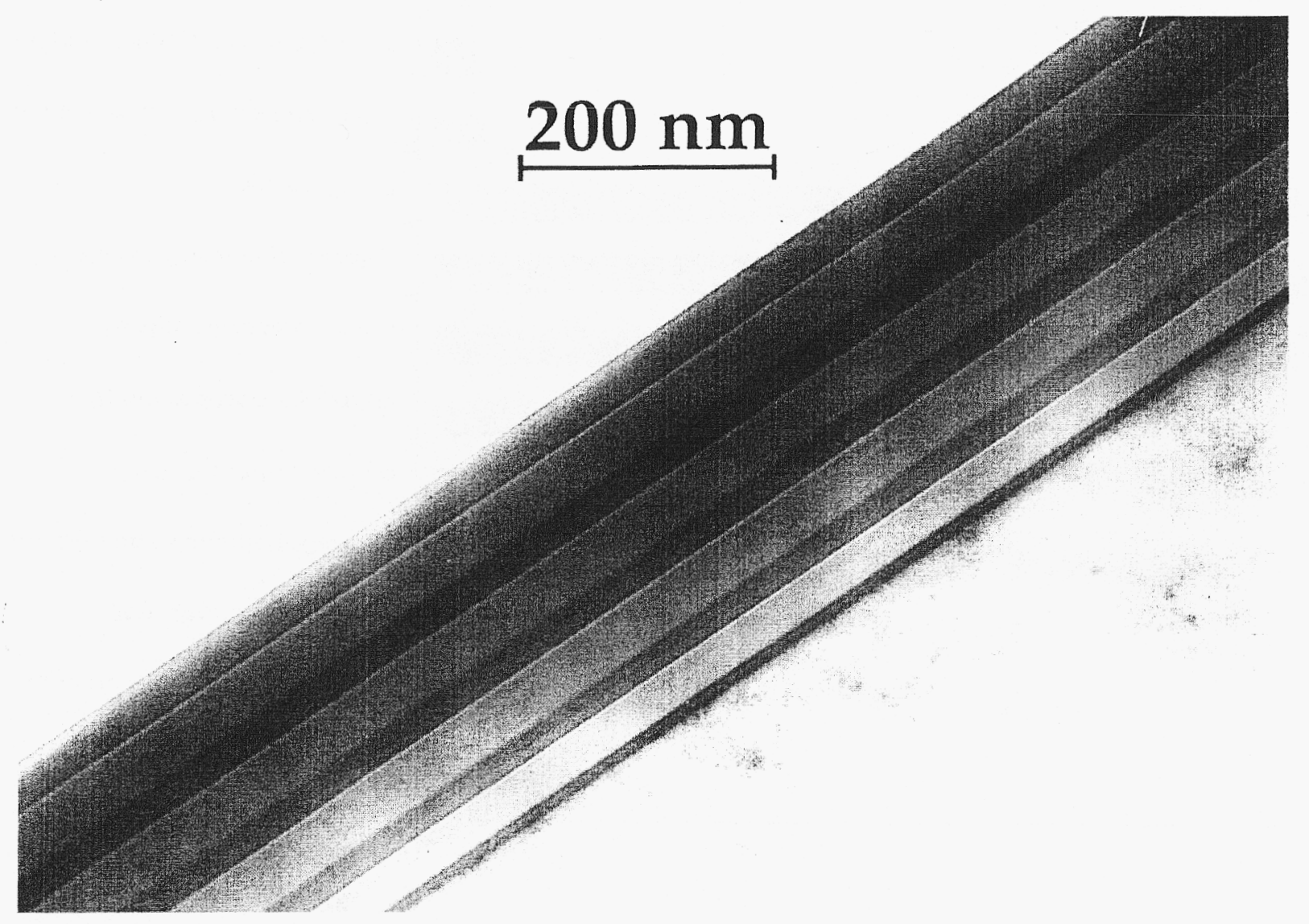


Fig. 5: Comparison of corrosion resistance of die pins treated with various surface treatments, the most successful being a duplex coating with a filtered arc multilayer coating. Courtesy of D. Bhat

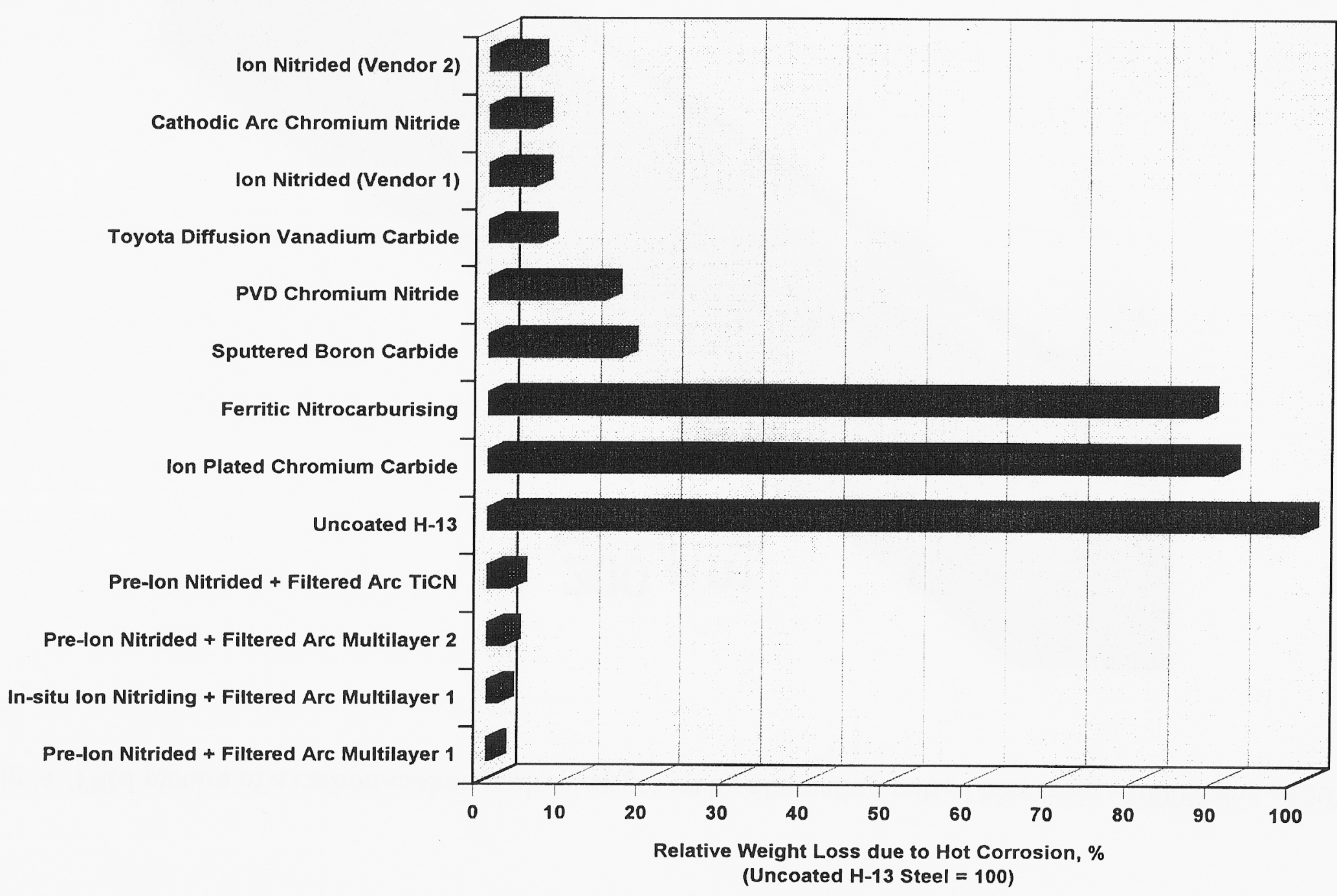


Fig. 6: Comparison of thermal fatigue behavior of coated and uncoated die pins. The multilayer produced in the filtered cathodic arc system prevents surface cracking that is found in the uncoated part. Courtesy of D. Bhat.
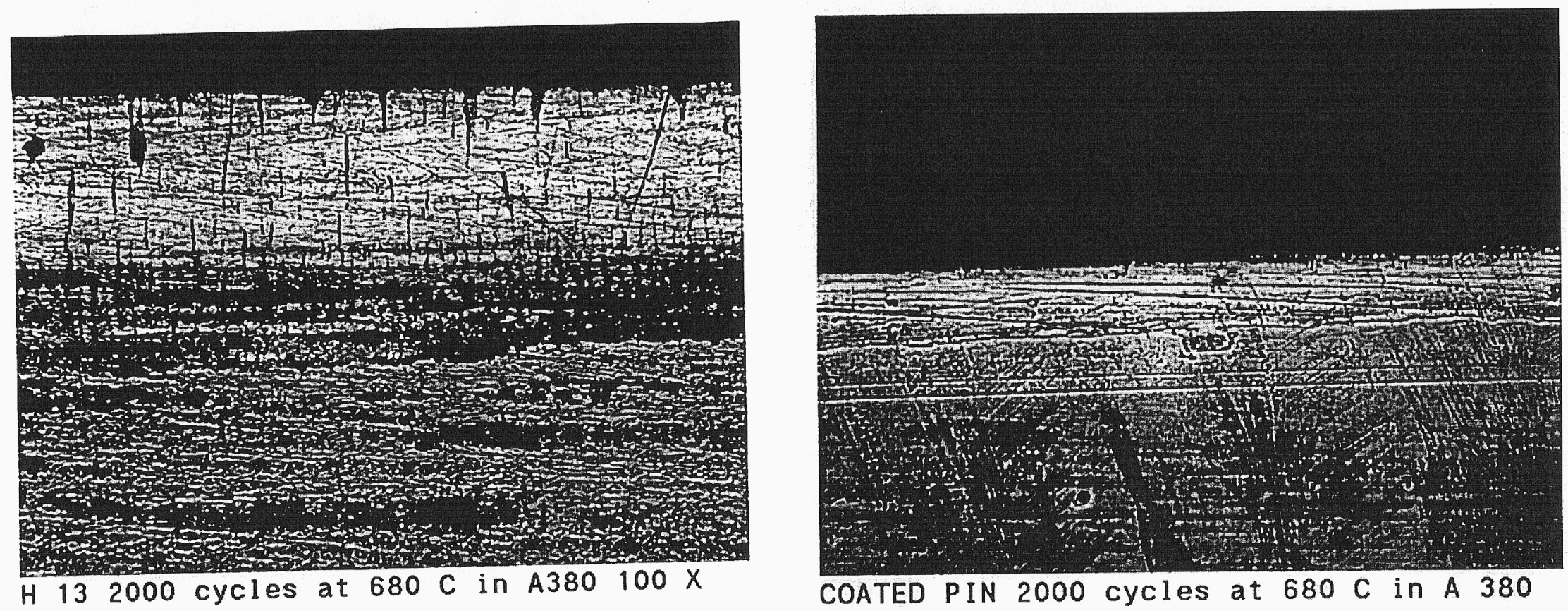

COATED PIN 2000 cycles at $680 \mathrm{C}$ in A 380

\section{Uncoated H13 (2000 cycles) Multilayer Coated}


Fig. 7: Copper trench filling using the MePIIID process (filter cathodic arc with tailored pulse biasing); (a) shows an example of premature closing of trench avoided by the MePIIID process (b) discussed in the text. Figure courtesy of $\mathrm{O}$. Monteiro

a.

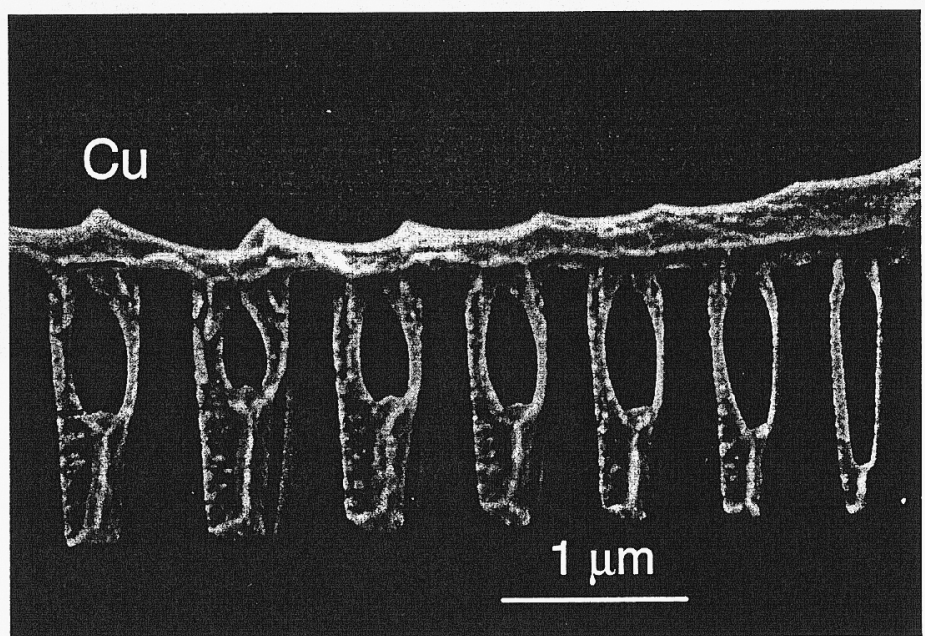

b.

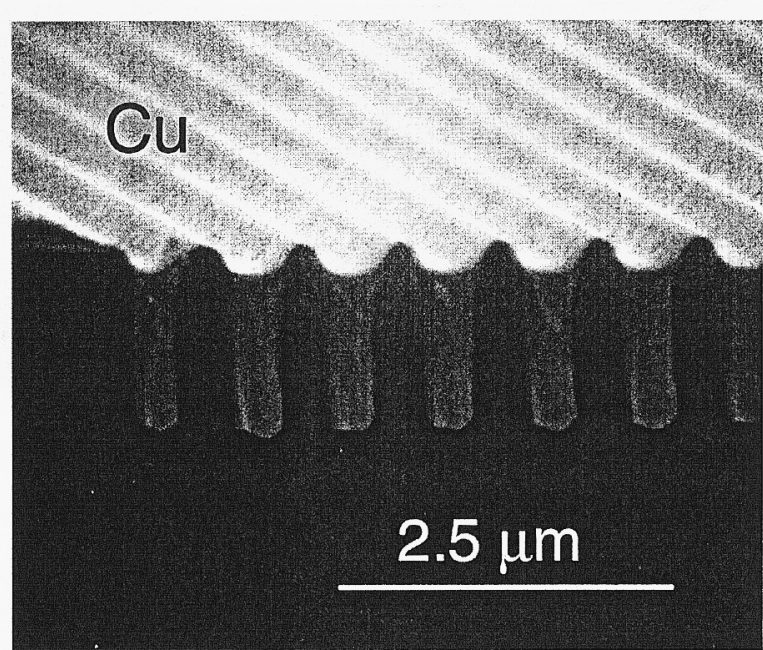


Fig. 8: Deposition of $20 \mathrm{~nm}$ tantalum diffusion barrier with 7:1 aspect ratio using the MePIIID process, figure courtesy of $\mathrm{O}$. Monteiro

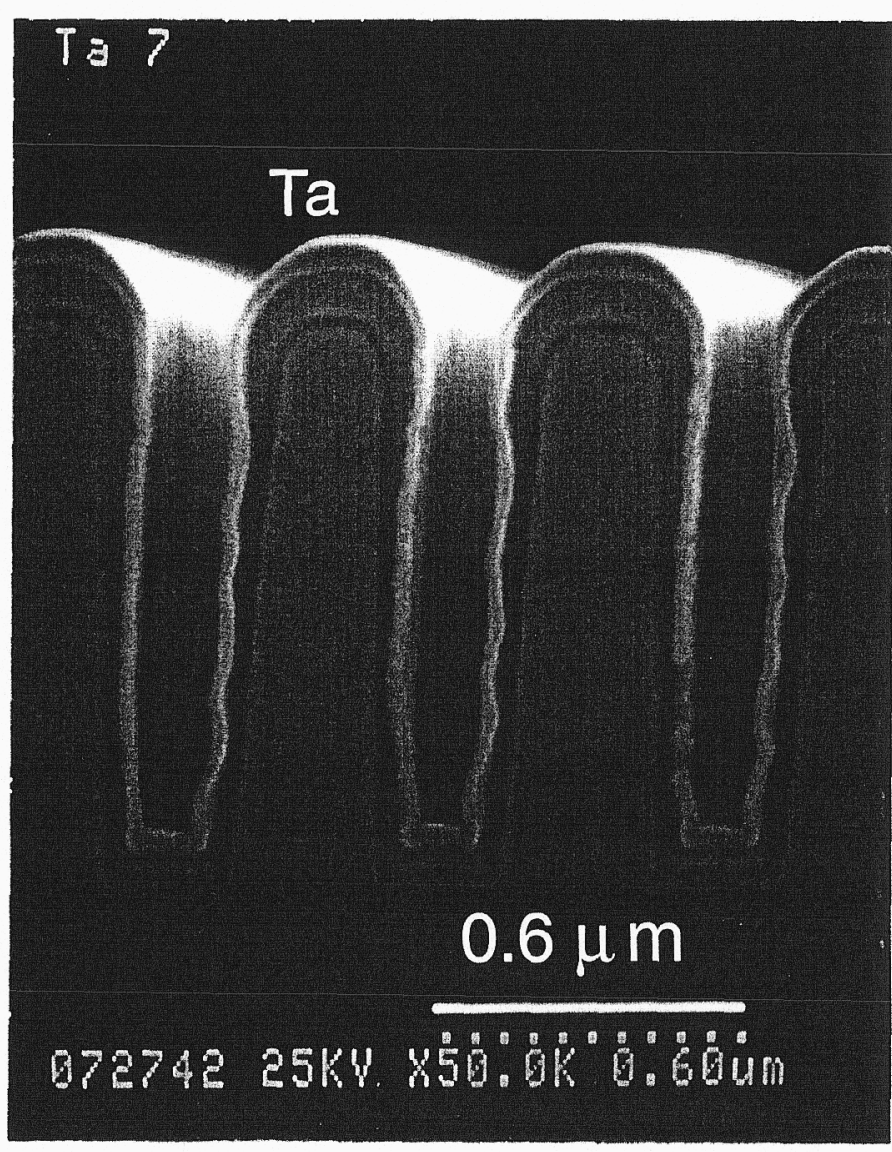

